\title{
A CONSTRUÇÃo DE COMUNIDADES EDUCATIVAS E PEDAGógICAS: PARA UMA FORMAÇÃo E PRÁtICA PEDAGÓgICA ARTICULADA
}

THE CONSTRUCTION OF EDUCATIONAL AND EDUCATIONAL COMMUNITIES: FOR AN ARTICULATED TRAINING AND EDUCATIONAL PRACTICE

LA CONSTRUCCIÓN DE COMUNIDADES EDUCATIVAS Y PEDAGÓGICAS: PARA LA FORMACIÓN Y PRÁTICA EDUCATIVA ARTICULADA

\begin{abstract}
Pedro Duarte ${ }^{1}$
RESUMO

O presente trabalho pretende refletir sobre as relações entre as instituições de ensino superior (universidades e institutos politécnicos) e as intuições de ensino não superior (escolas básicas e secundárias) no âmbito da formação inicial de professores. Essa reflexão relaciona-se implicitamente com o processo de supervisão na formação inicial, e a forma como esta contribui para formação de professores que refletem sobre a sua ação, assumindo-se que essa prática é sustentada num conhecimento praxiológico simultaneamente individual e coletivo. Tendo em conta essa reflexão, e tomando em consideração os pressupostos teóricos explorados, pretende-se refletir e indicar possíveis problemas/desafios inerentes ao processo de supervisão na formação inicial de professores e à relação existente entre as instituições de ensino superior e as instituições de ensino não superior. Tomando como base os problemas/desafios indicados, propõe-se um sistema/estrutura (Comunidades Educativas e Pedagógicas) de partilha e colaboração entre as diferentes organizações, o que possibilita uma formação inicial de professores integrada e integral que valoriza o continuum teoria e prática.
\end{abstract}

PALAVRAS-CHAVE: Formação inicial de professores. Ensino superior. Ensino não superior. Supervisão pedagógica.

\begin{abstract}
This paper aims to reflect on the relationship between higher education institutions (universities and polytechnic institutes) and intuitions of non-higher education (primary and secondary schools) in the context of initial teacher training. This reflection is implicitly related to the process of supervision in initial formation, and how this contributes to the formation of teachers who reflect on their action, assuming that this practice is sustained in a praxiological knowledge simultaneously individual and collective. Taking into account this reflection, and taking into account the theoretical assumptions explored, it is intended to reflect and indicate possible problems / challenges inherent to the supervision process in the initial teacher training and to the relationship between higher education institutions and educational not higher education institutions. Based on the problems / challenges indicated, it is proposed a system / structure (Educational and Pedagogical Communities) of sharing and collaboration between the different organizations that enables an integrated and integral initial teacher training that values the continuum theory and practice.
\end{abstract}

KEYWORDS: Initial teacher education. Higher education. Compulsory education. Supervision.

\section{RESUMEN}

Este documento tiene como objetivo reflexionar sobre la relación entre las instituciones de educación superior (universidades y escuelas politécnicas) e intuiciones de educación no superiores (primaria y secundaria) en la formación inicial del profesorado. Esta reflexión se refiere implícitamente con el proceso de supervisión en la formación inicial, y cómo esto contribuye a la formación de los maestros que se reflejan en su acción, en el supuesto de que esta práctica se sustenta en un conocimiento praxeológico tanto individual como colectivo. En vista de esta reflexión, y teniendo en cuenta los supuestos teóricos exploradas, se pretende reflexionar indicar

${ }^{1}$ Mestre em Estudos Profissionais Especializados em Educação pelo Instituto Politécnico do Porto Escola Superior de Educação. Professor da Associação para o Desenvolvimento de Matosinhos. Matosinhos, Portugal. E-mail: pedropereira@ese.ipp.pt - ORCID: http://orcid.org/0000-0002-3048-6959

Submetido em: 12/08/2016 - Aceito em: 27/09/2016

\begin{tabular}{|l|l|l|l|l|l|l} 
(C) Rev. Inter. Educ. Sup. & Campinas, SP & v.2 & n.3 & p.405-429 & set./dez. 2016 & ISSN 2446-9424
\end{tabular}


posibles problemas / retos inherentes en el proceso de supervisión en la formación inicial de los maestros y la relación entre las instituciones de educación superior e instituciones educativas. Sobre la base de los problemas / desafíos indicados, propone un sistema / estructura (Educación y Comunidades Pedagógicas), el intercambio y la colaboración entre las diferentes organizaciones, posibilitando una formación inicial de profesores, integrada e integral, que valora la teoría y la práctica como un continuum.

PALABRAS CLAVE: Formación inicial del profesorado. Educación universitaria. Educación no universitaria. Supervisión.

\section{Introdução}

Reconhece-se, fazendo uso das palavras de Haggarty (2002, p. 11), que "Research on initial teacher education confirms what those involved in teacher education have always known: learning to teach is complex and demanding; and teaching - or supporting the endeavours of - those who are learning to teach is difficult”. Assume-se, desta forma, que o processo de formação de professores é complexo, e tem sido amplamente estudado pela comunidade acadêmica, através de investigações de diferentes dimensões inerentes ao processo em estudo (CAIRES; ALMEIDA; VIEIRA, 2012), e as múltiplas perspectivas existentes identificam a riqueza e a complexidade inerentes ao processo de formação profissional dos docentes (ALTAN; SAĞLAMEL, 2015).

O presente trabalho pretende servir de reflexão sobre a possível criação de sistemas/estruturas de colaboração e partilha entre as instituições de ensino superior e de ensino não superior (escolas do ensino básico e secundário).

Tendo em conta esse objetivo geral, pretende-se:

- elucidar a forma como as instituições de ensino superior se assumem como principais instituições de formação inicial de professores;

- ilustrar o que, no âmbito da literatura da espacialidade, se apresenta como preponderante no processo de formação de professores;

- apresentar possíveis desafios no âmbito da formação inicial de professores tendo por base o que foi reconhecido como preponderante no processo de formação de professores;

- apresentar uma proposta de sistema/estrutura (Comunidades Educativas e Pedagógicas) que possibilitam responder de forma integrada aos desafios apresentados.

Em concordância com o explorado, o presente texto apresenta quatro seções. Na primeira, explora-se a importância da formação de professores, enquadrando diferentes perspectivas e sustentações sobre o tema em análise. Na segunda, estudam-se as possíveis relações entre teoria e prática na docência e na formação dos professores. A terceira seção centra a análise na relevância das instituições superiores para a formação de professores e na sua importância para a articulação e mobilização dos saberes (teóricos e práticos) na formação inicial de professores. Por fim, na quarta e última seção, propõe-se uma estrutura organizacional e que visa contribuir para novas formas de combinar os contributos das 
instituições superiores para a formação de professores, mas, também, assumir a importância das escolas de ensino não superior.

\section{A Formação Inicial de Professores: Dilemas e Relevância}

A formação de professores continua a ser um tema preponderante para diferentes agentes/organizações sociais: instituições de formação de professores; comunidade científica e investigativa; agentes políticos; agrupamentos de escolas ${ }^{2}$ e escolas (ESTRELA; FREIRE, 2009). Tal como é relembrado por Nóvoa (2007a, 2009), é importante ter em atenção que os diferentes relatórios publicados pela OCDE deram novo fôlego à discussão, e recolocaram o assunto no centro dos debates e políticas.

É necessário assumir a dificuldade de afirmação e reconhecimento, no âmbito social, do conhecimento específico da docência (NÓVOA, 2002). Note-se que, nas fases mais iniciais de educação, esta situação ainda se torna mais profunda, uma vez que a visão social tende a menosprezar os saberes específicos desses professores, considerando-os responsáveis por trabalhos menores, sem qualquer especificidade ou competências próprias, limitando-se, no seu essencial, a ter que conhecer o currículo (ROLDÃO, 2005). Todavia, diferentes investigações têm reconhecido que a formação dos professores é um elemento basilar na promoção de melhores resultados dos alunos (MARCELO, 2009; NÓVOA, 2009), uma vez que a qualidade de um sistema educacional de ensino é, em longa medida, sustentada e influenciada pela qualidade dos professores (MALM, 2009).

Desta forma, torna-se imprescindível reconhecer, à semelhança de Perrenoud (2001), a existência de competências e saberes específicos da docência. De acordo com Roldão (2005), o conhecimento específico dos professores é ensinar ${ }^{3}$. Face ao exposto, encara-se como imprescindível que os (futuros) professores desenvolvam e dominem competências e conhecimentos técnicos que não lhes são inatos. Tomando por base o referido, admite-se a existência de elementos específicos à profissão docente que não são compreendidos ou acessíveis ao restante da sociedade (SHULMAN, 1987), que é uma característica essencial para a afirmação e reconhecimento dos professores como profissionais intelectuais (YOUNG; BOYD, 2010).

Todavia, tal como já foi aludido, e de acordo com Nóvoa (2007b), na contemporaneidade, o professor continua a ser encarado como um profissional sem grande formação ou sem grande especificidade, promovendo-se o desprestígio da profissão docente.

\footnotetext{
${ }^{2}$ Em Portugal as escolas públicas associaram-se, atualmente e na sua maioria, e encontram-se agrupadas com outras escolas do mesmo nível de ensino ou de níveis de ensino diferentes. Tenha-se em atenção que os agrupamentos de escolas são as organizações e entidades de gestão, sendo que os processos de decisões estão centrados no agrupamento e não nas escolas.

3 Tenha-se em atenção que Roldão (1999, 2004), encara ensinar como fazer aprender
} 
Face a este paradigma, a formação de professores (nas suas diferentes dimensões: formação contínua, formação especializada e formação inicial), tem a potencialidade de evidenciar profissional e socialmente o estatuo da profissão docente (NUNES; NUNES, 2013), uma vez que através da formação é possível legitimar o saber específico dos professores e da docência (NÓVOA, 1992). Este tipo de perspectiva enquadra a "afirmação profissional sustentada na especificidade, técnica e científica do exercício da função de ensinar - entendida como a promoção, sustentada em conhecimento profissional, da aprendizagem de alguma coisa por alguém” (ROLDÃO, 2014, p. 62).

Tomando a perspectiva de Afonso (2014), reconhece-se que a formação de professores e o aumento da sua duração foi uma conquista significativa para a classe docente, uma vez que reforça o valor e a importância da profissão, consagrando os seu valores e conhecimentos específicos e próprios. Reconhece-se, também, a importância desta formação se desenvolver em instituições superiores próprias, implicando a construção e sistematização de saberes específicos, que não são de fácil acesso ao restante população (CUNHA, 2008) e que se distinguem dos saberes de quaisquer outros agentes sociais (ROLDÃO, 2008).

Em concomitância com o apresentado, assume-se que as universidades e demais instituições de ensino superior são fundamentais para "promote an academic and critical image of teachers as public intellectuals, where critical knowledge production is a defining feature of the teaching profession” (YOUNG; BOYD, 2010, p. 10). Fica, deste modo, patente que, à semelhança do que é defendido por Roldão (2014), a formação superior é extremamente relevante para a que os professores adquiram estatuto de profissionais intelectuais, contrariando algumas tendências de naturalização da ação pedagógica e da profissão docente.

A par da valorização da profissão e do saber específico da docência, existe outro elemento fundamental para a formação: a complexidade do processo educativo. É imprescindível reconhecer-se que os professores e o seu trabalho se alteraram profunda e drasticamente (YOUNG; BOYD, 2010). Atualmente, o professor abarca diferentes desafios e responsabilidades, sendo-lhe exigido que domine diferentes áreas que ultrapassam a sala de aula e os conteúdos específicos que explora em contexto pedagógico, como: metodologias educativas; modelos de aprendizagem; psicologia do conhecimento; sociologia da educação; gestão curricular; gestão de conflitos; administração e gestão escolar; ... (CUNHA, 2008). Aliando estes elementos ao alargamento das responsabilidades das escolas, que contínua e progressivamente assume mais missões e funções (NÓVOA, Nada substitui o bom professor, 2007b), reconhece-se que o processo educativo, na sua dimensão lata e plena, é complexo, e requer a formação adequada. Concretamente, após o processo de massificação do ensino e da educação formação, perfilou-se uma maior responsabilização dos professores, o que implicou um maior e mais profundo conhecimento dos saberes profissionais (ROLDÃO, Gestão Curricular - Fundamentos e Práticas, 1999; MESQUITA, FORMOSINHO; MACHADO, Formação e trabalho: tradição e inovação nas práticas docentes, 2014). 
Relembra-se, ainda, que a formação dos professores se inicia muito antes do acesso às instituições de ensino superior. O processo de formação destes profissionais principia-se com as suas experiências, enquanto alunos, ao longo da escolaridade básica (FLORES, 2010; NUNES; NUNES, 2013), como observadores de diferentes professores (HAGGARTY, 2002). Ao contrário do que acontece na maioria das profissões, os docentes já conhecem, com significativa relevância, o contexto onde irão exercer a sua profissão: as salas de aula e as escolas (FLORES, 2010).

Desta forma, os futuros professores já possuem representações sobre a profissão docente, a sua profissionalidade e as competências que lhe estão associadas, ainda antes de se iniciarem na formação inicial (MESQUITA, 2015). Todavia, e tendo como base as reflexões de Roldão (2005), mesmo que o processo de formação docente e de construção da identidade profissional dos professores se inicie antes do ingreso nas instituições de ensino superior, é só durante a formação inicial que os professores em formação compreendem a quantidade e complexidade dos saberes profissionais inerentes à prática pedagógica e à profissão docente.

Face ao referido reconhece-se a importância da formação de professores em três pilares distintos, que podem ser espelhados da seguinte forma:

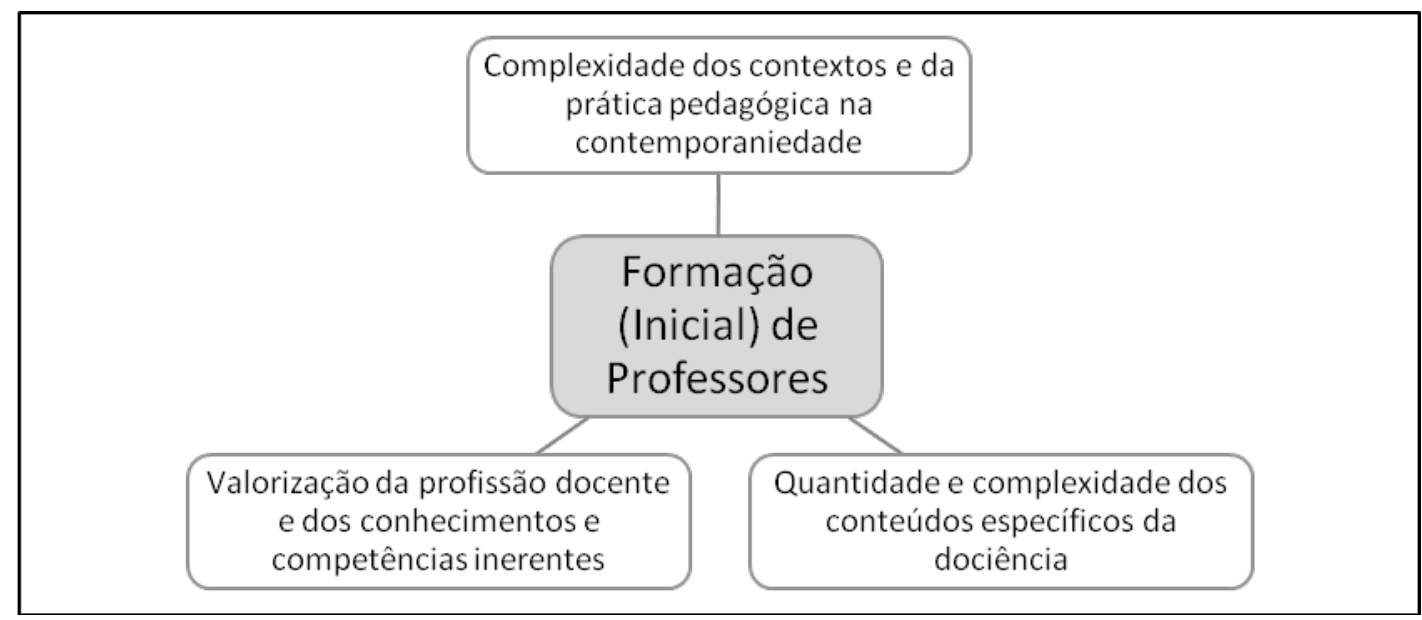

Esquema 1 - Os basilares que sustentam a importância da Formação (Inicial) de Professores Fonte: (esquema próprio)

O esquema, permite ilustrar, de acordo com o que foi apresentado anteriormente, os diferentes elementos que sustentam e justificam a formação de professores, seja ela a formação inicial, contínua ou de especialização. Como já foi referido, apresentam-se três pilares que se consideram essenciais:

a) Complexidade dos contextos e da prática pedagógica na contemporaneidade: tal como foi aludido, assume-se que as missões e funções da escola complexificaram-se com a massificação do ensino, implicando uma complexificação inerente à ação dos professores e da sua prática profissional;

b) Quantidade e complexidade dos conhecimentos inerentes à prática pedagógica: a

\begin{tabular}{|l|l|l|l|l|l|l}
\hline (C) Rev. Inter. Educ. Sup. & Campinas, SP & v.2 & n.3 & p.405-429 & set./dez. 2016 & ISSN 2446-9424
\end{tabular} 
profissão docente contempla um conjunto vasto de sabres profissionais (conteúdos e competências) que necessitam ser desenvolvidos e aprendidos pelos futuros professores em instituições de ensino específicas;

c) Valorização da profissão docente e dos conhecimentos e competências inerentes: a valorização social da profissão de professor encontra-se associada à valorização dos conhecimentos inerentes à sua profissão. Para que sejam valorizados é necessário contrariar-se a ideia de naturalização da docência, sendo, para isso, necessário reconhecer que os saberes próprios da profissão são vastos e complexos e implicam um processo de investigação científica e de aprendizagem.

Tomando o esquema e explicação anteriores, verifica-se a suma relevância e importância da formação de professores. Todavia, ainda que se assuma os contributos das instituições de ensino superior para a formação inicial de professores, é inegável a necessária integração dos professores em formação em contextos reais de ensino não superior, para a promoção de saberes vivenciados pelos estudantes, que surgem na relação entre aspectos teóricos e práticos da ação docente.

\section{Teoria e Prática no Saber e Formação Docente: Relações Possíveis}

Tal como já foi referido, o processo de formação de professores é complexo, exigente e difícil. Um debate com especial relevância neste âmbito, é a relação entre a teoria e a prática durante o processo de formação de professores (HAGGARTY, 2002). De acordo com o que é apresentado por Ketter e Stoffel (2008), verifica-se alguma desconexão entre os professores no terreno e os formadores de professores. Por sua vez, Sultana (2005), alerta para o fato de existir quem considere que as instituições de formação de professores tendem para o academicismo e para a teorização. Esta situação pode ser enquadrada num debate mais amplo em que se tenta perceber as relações entre a teoria e a prática no contexto do ensino e da formação de professores.

Face a esta situação é possível encontrar-se duas perspectivas diferentes. Por um lado, alguns defendem que a formação de professores deve ser iminentemente prática, semelhante a um "treino", em que os futuros docentes aprendem o que fazem em específico para cada situação (para a situação x a ação correta é y) (HAGGARTY, 2002; CAIRES; ALMEIDA; VIEIRA, 2012). Este modelo assume a profissão de professor como iminentemente técnica, em que se apresentam um conjunto de técnicas aos futuros professores e estes, após treino, têm a potencialidade de aplicá-las em contexto real (COCHRAN-SMITH, 2000). Esta perspectiva, quando realizada durante a formação inicial de professores, vincula a ideia, aos professores em formação, que o processo pedagógico se sustenta em tentativa e erro, e não num processo de pensamento cuidado e refletido, fazendo com que os futuros professores não desenvolvam os princípios teóricos necessários para a compreensão das implicações sociais e éticas inerentes à sua prática pedagógica (SULTANA, 2005). 
Por outro lado, há quem defenda que a educação de professores deve ser encarada como um processo "educativo", em que se incorporam aspectos teóricos, práticas e situações de ações concretas ao longo da formação (HAGGARTY, 2002; CAIRES; ALMEIDA; VIEIRA, 2012). Estas perspectivas surgem numa fase posterior e são consideravelmente diferentes, uma vez que enfatizam a necessidade de se promover uma formação mais construtivista e integral, uma vez que se afastam da transmissão tradicional. A par disso, este paradigma legitima que a ação docente engloba aspectos como a reflexão, o trabalho colaborativo, uma relação prática-teoria no trabalho pedagógico, que se encontra totalmente oculta e menosprezada na perspectiva anterior (COCHRAN-SMITH, 2000).

Para se compreender este debate é fundamental integrar-se as diferentes perspectivas sobre o que é teórico e prático no contexto educativo. Tal como é alertado por Flores (2010) e por Altan e Sağlamel (2015), por vezes considera-se que a prática é o que acontece no contexto educativo, nas escolas com as crianças e jovens, e a teoria o que é aprendido nas instituições de formação de professores. Por sua vez, Pérez Gómez (2010), reconhece que há quem interprete e a relação teoria-prática como lineal e unidirecional, em que a prática só existe porque é justificada e sustentada pela teoria.

É porém necessário repensar estas tensões entre teoria e prática (HAGGARTY, 2002). Ao explorar-se as perspectivas de Shulman (1986) e de Nóvoa (2002), é possível compreender-se de forma mais complexa e integral o que está subjacente à teoria e prática no contexto da formação e prática docente.

De acordo com Shulman (1986) os saberes profissionais relacionados com a prática docente convergem em três domínios: i) fontes de conhecimento da prática do docente; ii) a forma como esse conhecimento é construído; iii) as implicações práticas desse conhecimento na ação pedagógica. Com um pensamento complementar, Nóvoa (2002, p. 27), considera que o conhecimento profissional dos professores

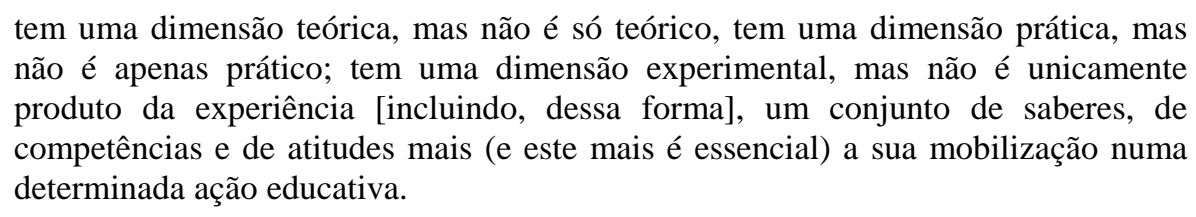

Face ao apresentado, afirma-se que a relação entre a teoria e prática é mais intrínseca do que se atendia, porque pretende-se que ambos contribuem, equitativamente, para a prática pedagógica dos professores. Para se compreender o fenómeno, pode-se considerar que, originalmente, a docência e todos os aspectos relacionados com a ação dos professores eram, iminentemente, práticos, e só mais tarde se teorizaram, o que dificulta a formalização e reconhecimento dos conhecimentos profissionais relacionados com o ato de ensinar (ROLDÃO, Função docente: natureza e construção do conhecimento profissional, 2008).

Todavia, atualmente, não faz sentido pensar-se a profissão docente como exclusivamente prática. É essencial não se reduzir a prática pedagógica a elementos

\begin{tabular}{l|l|l|l|l|l|l} 
(C) Rev. Inter. Educ. Sup. & Campinas, SP & v.2 & n.3 & p.405-429 & set./dez. 2016 & ISSN 2446-9424
\end{tabular}


meramente práticos ou exclusivamente teóricos (FORMOSINHO, 2015). É imprescindível adequar-se, por um lado, as diferentes teorizações que incorporaram a definição de "o que ensinar, como ensinar, a quem e de acordo com que finalidades, condições e recursos" e que se integram e incorporam "num único saber integrador, situado e contextual - como ensinar aqui e agora -, que se configura como ‘prático'” (ROLDÃO, 2008, p. 98).

Tomando-se em consideração os trabalhos de Shulman (1986; 1987), também se reconhece que os conhecimentos referentes à ação docente contemplam as dimensões praxiológicas da prática pedagógica. De acordo com o autor, é possível estruturar-se o conhecimento referente à ação docente em diversas categorias. Numa fase inicial, o autor (SHULMAN, 1986), indica três saberes específicos para a prática profissional dos docentes: i) Contente Knowledge; ii) Pedagogical Content Knowledge; iii) Curricular Knowledge. Num trabalho subsequente, Shulman (1987) especifica com maior pormenor e mais especificidade as categorias da seguinte forma: i) Content Knowledge; ii) Curricular Knowledge; iii) General Pedagogical Knowledge; iv) Pedagogical Content Knowledge: v) Knowledge of educational contextsvi) Knowledge of educational ends, purposes, and values, and their philosophical and historical grounds; vii) Knowledge of learners and their characteristics. Tomando os artigos deste autor, mesmo com as alterações já ilustradas, podese perfilar, no seu todo, sete categorias distintas:

i) Content Knowledge: relacionado com conhecimento científico de cada uma das áreas curriculares/disciplinas. Além de conhecer e ter apropriado o conhecimento científico, os professores têm que ser capazes de relacionar e articular os conteúdos das diferentes áreas científicas para que tenham a possibilidade de construir redes e percursos que melhor possibilitem a aprendizagem dos seus alunos. Recordando as palavras de Shulman (1986, p. 14), “Those who can, do. Those who understand, teach”.

ii) Curricular Knowledge: através do conhecimento curricular os docentes têm a possibilidade de gerir e articular (de forma horizontal e vertical) o currículo, os conteúdos e competências que deseja explorar com os seus estudantes. O conhecimento curricular é, também, aquele que permite ao professor optar e ajustar o currículo ao contexto da escola e da turma e articular o seu trabalho pedagógico com o que está a ser explorado nas restantes áreas disciplinares.

iii) General Pedagogical Knowledge: relativo aos referenciais do professor sobre os princípios educacionais e pedagógicos gerais que devem ser mobilizados no processo pedagógico de forma a proporcionar melhores e mais significativas aprendizagens.

iv) Pedagogical Content Knowledge: homólogo ao anterior, mas referente ao que se poderia denominar de didática específica, no qual o professor articula os conhecimentos da didática geral com as características específicas de cada disciplina promovendo situações de aprendizagem que melhor correspondem às características específicas das diversas áreas 
curriculares.

v) Knowledge of educational contexts: relativo ao conhecimento do contexto educativo (nacional, regional e local), da comunidade educativa, assim como o trabalho que desenvolve com os restantes colegas, como forma de integrar o seu trabalho de professor num contexto específico da escola e da comunidade educativa.

vi) Knowledge of educational ends, purposes, and values, and their philosophical and historical grounds: referente ao posicionamento paradigmático que os professores assumem face às funções da escola, aos objetivos da educação, aos valores inerentes à educação e aos aspectos históricos e filosóficos que sustentam a existência de escolas e o seu enquadramento na sociedade.

vii) Knowledge of learners and their characteristics: relativo ao conhecimento que o professor constrói dos seus estudantes e das suas características, de forma que a sua ação pedagógica melhor corresponda às necessidades próprias de cada aluno.

O que se verifica, com os trabalhos de Shulman, é que os conhecimentos próprios para a ação pedagógica são diversos e integram, simultaneamente, componentes teóricos e práticos. Verifica-se ainda que o posicionamento de Shulman se encontra enquadrado no que é defendido por Aimaretti (2015), que reconhece que o desenvolvimento dos conhecimentos e competências pedagógicas se estrutura, desenvolve e reconstroi através da interação com os contextos educativos específicos.

Face ao apresentado, verifica-se que o saber docente se configura, no seu essencial, como um saber produzido e desenvolvido no contexto da práxis profissional (ROLDÃO, Professores para quê? Para uma reconceptulização da formação de profissionais de ensino, 2004). Em concomitância com este pressuposto, Ribeiro (2015, p. 361) indica que o contexto real da prática pedagógica pode e dever ser encarado como um espaço de "construção e reconstrução do saber do saber praxiológico do professor, na sua dupla dimensão: de reflexão epistemológica e de intervenção pragmática”.

Neste contexto, o ato de ensinar é encarado como um desafio intelectualmente desafiante, uma vez que implica que os professores integrem aspectos relacionados com os pressupostos teóricos, com os valores e a ética docente e as necessidades próprias de cada contexto (HAGGARTY, 2002). É neste âmbito que a teoria e a prática se conjugam e fundem, num saber e numa competência complementar e simultaneamente teórica e prática, que possibilita a integração e construção de conhecimento profissional, configurando os professores como profissionais intelectuais (MALM, 2009), que examinam e refletem sobre sua própria prática pedagógica, de forma a que seja possível refinar e melhorar as suas ações como docentes (HAGGARTY, 2002). 


\section{O Papel das Instituições de Ensino Superior na Articulação dos Dois Conceitos}

Mesmo assumindo essa perspectiva praxiológica do conhecimento docente, não é possível reconhecer-se ou indicar-se consensos gerais na definição do papel das instituições de formação de professores, uma vez que não é consensual o que é necessário ensinar aos futuros professores e como é que eles devem aprender. Desta forma, definir-se um modelo de formação de professores que apresente melhores resultados e que possa ser considerado "o melhor modelo” é uma total impossibilidade e não há uniformidade sobre as perspectivas neste assunto (SULTANA, 2005). Contudo, tendo por base o que é apresentado por Malm (2009, p. 88), assume-se que a formação de professores deve incidir nos seguintes aspectos:

- developing teachers' capacities for creative and reflective thought;

- enhancing critical thinking;

- heightening teachers' philosophical and pedagogical awareness;

- emphasising the cognitive as well as emotional aspects of teaching;

- training teachers' capacities for empathy and interpersonal collaboration;

- developing a personal understanding of the implications of teaching perceived as a moral and ethical profession.

Todavia, admite-se que a formação de professores toma por base diferentes ações e tomadas de posição de acordo com o paradigma de professor que assume (SULTANA, 2005), uma vez que se reconhece a existência de diferentes perspectivas sobre a forma como os estudantes aprendem e de que forma os professores devem corresponder a essas necessidades (HAGGARTY, 2002). Tomando como base o que foi apresentado, assume-se que a perspectiva de professor-investigador/ professor reflexivo ${ }^{4}$ é uma das que melhor correspondem aos desafios e condicionantes referidas.

Através da prática reflexiva, os professores têm a possibilidade de refletir sobre as suas próprias práticas pedagógicas, mas, também, sobre os referenciais teóricos que implicam e derivam das suas próprias práticas (ZEICHNER, 1993), que possibilitará aos docentes estruturarem as suas orientações gerais e pessoais para a sua ação em sala de aula (ALTAN; SAĞLAMEL, 2015). É através da reflexão e reflexividade, que os professores têm o potencial para otimizar a sua prática individual e implicá-la no processo mais amplo e alargado de inovação pedagógica (PERRENOUD, 1999). Assumindo que se pode encarar “a reflexividade como um exercício intencionalmente voltado para a construção de hipóteses de respostas aos desafios do quotidiano profissional” (RIBEIRO, 2015, p. 360), reconhece-se a sua relevância no processo de auto-conhecimento e auto-formação dos professores e da sua ação pedagógica (MCKENZIE, 2015).

\footnotetext{
${ }^{4}$ Ainda que se reconheça a possibilidade de distinguir os dois paradigmas, o posicionamento e sustentação teórica escolhidos torna-os de difícil distinção e dissociação.
} 
Como referem vários autores (AlARCÃO, 1996, 2001a; OLIVEIRA; SERRAZINA, 2002; ROLDÃO, 2008), esta prática reflexiva implica, obrigatoriamente, no processo de investigação dos professores. É através deste processo que os docentes têm, também, possibilidade de contribuir para a emancipação da profissão docente (ZEICHNER, 1993), uma vez que estruturaram e vinculam os conhecimentos próprios e específicos desta profissão (ROLDÃO, Professores para quê? Para uma reconceptulização da formação de profissionais de ensino, 2004). Em concomitância com esta linha de pensamento, é possível considerar-se que a prática reflexiva é fundamental no desenvolvimento profissional dos docentes, na sua autonomia, responsabilidade, criatividade e capacidade de investigar sobre a sua ação enquanto professores (MALM, 2009). Face ao exposto, assume-se que a investigação sobre e das práticas docentes deverá possibilitar a melhoria da ação pedagógica e da promoção de aprendizagens (ALARCÃO, Professor-investigador: Que sentido? Que formação? 2001a), enquadrando o processo investigativo como "construção do saber, saber fazer, saber ser e saber transformar” (RIBEIRO, 2015, p. 361) por parte do professorinvestigador.

Este processo implica que os docentes, sistematicamente, se interroguem sobre as suas práticas e sobre as opções inerentes às mesmas (CHERUVUA, 2014). Ao perpetuar este tipo de ação reflexiva, os docentes são capazes de melhorar a aprofundar as suas competências, capacidades e conhecimentos elementares da ação pedagógica, e de integrá-los, de forma coerente e contínua, na ação enquanto professores e na resolução de problemas próprios da docência (LARRIVEE, 2000), o que possibilitará uma transformação pessoal e uma melhoria da sua ação pedagógica (CHERUVUA, 2014).

Em concordância com o que foi apresentado, reconhece-se que a prática reflexiva, como elemento estrutural para ação docente e para a construção do seu saber profissional, deve assumir-se como um componente essencial e estrutural dos diversos cursos de formação de professores (LARRIVEE, 2000; MCKENZIE, 2015; AIMARETTI, 2015), o que possibilitará que a formação de professores se afirme como fundamental para o desenvolvimento de diversas competências nos futuros professores que sustentarão e possibilitarão um efetiva mudança (MESQUITA; FORMOSINHO; MACHADO, Formação e trabalho: tradição e inovação nas práticas docentes, 2014).

De acordo com o que é referido por Malm (2009), os programas de formação de professores incluem prática integrada nos seus cursos. Este tipo de situação com maior caráter prático, pode incluir situações de aprendizagem, planificação de aulas, observação de situações e aulas concretas, dinamizar sessões de acompanhamento e apoio a estudantes e, inevitavelmente, planificar, dinamizar e refletir sobre as suas próprias aulas enquanto professores (ALTAN; SAĞLAMEL, 2015). Esta prática, no contexto de formação de professores, tende a culminar no processo de Estágio e/ou de Prática Educativa Supervisionada - Supervisão. 
É imperativo que se tenha em consideração que o conceito de supervisão é polissêmico (OLIVEIRA-FORMOSINHO, 2003), podendo ser encarado como um processo complexo, sujeito a distintas interpretações (ALARCÃO; CANHA, 2013). Numa análise mais elementar e simples é possível considerar a "supervision as an interpersonal process in which the skilled practitioner or supervisor helps less skilled practitioners in relation to their professional growth and personal development of the supervisee” (IBARA, 2013, p. 239). No âmbito específico da formação de professores, este pode ser encarado como um período em que um professor em formação é orientado, no seu processo formativo e no desenvolvimento de saberes profissionais e na iniciação à docência, por um professor com mais experiência (OLIVEIRA-FORMOSINHO, 2003).

Recorde-se que, numa fase inicial, o conceito de supervisão assentava-se em modelos prescritivos que envolviam a avaliação dos professores em formação (que assumia um papel submisso face aos supervisores/especialistas), baseado em escalas e instrumentos de medida que mediam as diferentes prestações em análise (IBARA, 2013). A este paradigma associavam-se as perspectivas de inspeção, controlo (VIEIRA, 2009; MESQUITA, FORMOSINHO; MACHADO, 2012) punição e fiscalização (ALARCÃO; CANHA, 2013). Este modelo apresentava, porém, limitações, uma vez que não tinha em consideração aspectos humanísticos e poderia ser demolidor para o desenvolvimento profissional do professor em formação (IBARA, 2013).

De acordo com Oliveira-Formosinho (2003), as mudanças socais e educativas que marcam a contemporaneidade, nomeadamente a democratização dos estados, implicam que a formação de professores garanta a preparação dos professores para uma prática educativa democrática. Em consonância com este pressuposto democrático, está a promoção, por oposição ao modelo antecedente e em concordância com os valores democráticos, o respeito e colaboração entre todos os envolvidos (MESQUITA; FORMOSINHO; MACHADO, Supervisão da Prática Pedagógica e colegialidade docente. A perspetiva dos candidatos e professores, 2012). Em conformidade com o que foi aludido, reconhece-se que o processo de supervisão assenta nos valores da responsabilidade social e liberdade (VIEIRA, 2009), que se encontram inerentes e implícitos aos pressupostos democráticos que estão na gênese deste novo modelo de supervisão pedagógica.

Neste contexto, considera-se que a supervisão inicial de professores tem, implícita e obrigatoriamente, que se assumir como prática colaborativa entre todos os intervenientes envolvidos (MESQUITA; FORMOSINHO; MACHADO, Supervisão da Prática Pedagógica e colegialidade docente. A perspetiva dos candidatos e professores, 2012; IBARA, 2013). De acordo com esta perspectiva, assume-se que a supervisão é uma atividade com duplo sentido, acompanhamento e motorização, mas que deve centrar-se no desenvolvimento e na transformação dos intervenientes, enquanto uma dinâmica colaborativa, que toma em consideração o processo pedagógico, mas também as pessoas que o constituem (ALARCÃO; CANHA, Supervisão e Colaboração: Uma relação para o desenvolvimento, 2013), num contínuo processo de aprendizagem dos professores em formação, mas, também, dos 
supervisores.

Neste âmbito, reconhece-se que são os supervisores que assumem o papel de auxiliar no crescimento e desenvolvimento dos professores em formação, sendo essenciais para a promoção do autoconhecimento e dos saberes relacionados com as didáticas e a refletividade sobre e para a prática (ROLDÃO, 2014). São os supervisores que se responsabilizam pela árdua tarefa de auxiliar os professores em formação na transformação do saber em saber fazer (MESQUITA, 2015), auxiliando e acompanhando-os para que a supervisão se assuma como um período de aprendizagem, mobilização e integração de saberes teóricos e práticos, desenvolvimento de competências e de interação com diferentes agentes educativos (FORMOSINHO, 2015), num processo reflexivo e autonomizante (ALARCÃO; CANHA; Supervisão e Colaboração: Uma relação para o desenvolvimento, 2013). Esta noção torna-se especialmente relevante quando se assume que o professor, por ser um profissional intelectual, não se deve limitar a repetir práticas, ou a perpetuar os seus comportamentos em situações diferentes. O que se espera dos professores é que adaptem as suas estratégias face às diferentes circunstâncias em que leciona (MESQUITA, Formação inicial, profissão docente e competências para a docências. A visão dos futuros professores, 2015).

Em concomitância com esta visão, torna-se implícito que o supervisor se afirme como aquele que orienta e educa o futuro professor, esperando que se desenvolva pessoal e profissionalmente (RIBEIRO, Supervisão e o desenvolvimento da profissionalidade docente, 2000; MESQUITA; FORMOSINHO; MACHADO, Supervisão da Prática Pedagógica e colegialidade docente. A perspetiva dos candidatos e professores, 2012), numa dupla vertente de, simultaneamente, desafiar e apoiar o professor que supervisiona (ALARCÃO; CANHA, Supervisão e Colaboração: Uma relação para o desenvolvimento, 2013). Esta perspectiva assume contornos idênticos ao que Ibara (2013) denomina de abordagem colaborativa. Neste âmbito, espera-se que o processo de supervisão tenha como principal e mais relevante objetivo a formação dos professores em formação (MESQUITA; FORMOSINHO; MACHADO, Supervisão da Prática Pedagógica e colegialidade docente. A perspetiva dos candidatos e professores, 2012; ALARCÃO; CANHA, Supervisão e Colaboração: Uma relação para o desenvolvimento, 2013), reconhecendo a importância desde período formativo/educativo enquanto momento de preparação e iniciação ao pleno exercício docente (OLIVEIRA-FORMOSINHO, 2003) e de articulação entre a prática (in situ) e a teoria (MESQUITA, Formação inicial, profissão docente e competências para a docências. A visão dos futuros professores, 2015).

Face ao que foi aludido, a supervisão, no âmbito da formação inicial de professores, alicerça a sua relevância no progresso e fortalecimento da autonomia dos professores, assumindo-se como basilar no desenvolvimento e apropriação de saberes e competências pedagógicas, no aprofundamento de competências reflexivas, numa perspectiva de investigação-ação (VIEIRA, 2009; MESQUITA; FORMOSINHO; MACHADO, Formação e trabalho: tradição e inovação nas práticas docentes, 2014) num paradigma conducente à noção de professor reflexivo. 
A perspectiva já apresentada de professor como uma profissional reflexivo está, também, intimamente relacionada à perspectiva de comunidade educativa e colegialidade dos professores, em que se promovem e sustentam práticas colaborativas (SULTANA, 2005; MESQUITA; FORMOSINHO; MACHADO, Supervisão da Prática Pedagógica e colegialidade docente. A perspetiva dos candidatos e professores, 2012), em que na organização educativa os professores continuamente pensam sobre a sua prática e missão social, de forma, simultaneamente, avaliativa e formativa (ALARCÃO, Escola Reflexiva, 2001b; 2003). Esta noção torna-se especialmente relevante quando se compreende que o processo de formação docente necessita a inclusão de um processo de interação com comunidades educativas (CAIRES; ALMEIDA; VIEIRA, 2012), em que essas comunidades se afirmam como cruciais para a formação dos docentes (COCHRAN-SMITH, 2000; SIGUR_ARDOTTIR, 2005).

\title{
Uma Comunidade Educativa e Pedagógica
}

Face ao que se tem referido, reconhece-se a imperiosa necessidade de que as universidades e instituições de ensino superior responsáveis pela formação inicial de professores tenham a capacidade de construir e manter uma mais profunda e colaborativa relação com os professores no terreno e com as escolas (ALTAN; SAĞLAMEL, 2015; YOUNG; BOYD, 2010). Contudo, como é alertado por Cochran-Smith (2000), ainda não se estabeleceu, com algum consenso, se (e de que forma é que) as intuições superiores devem promover a melhoria das escolas.

Porém, e de acordo com a perspectiva apresentada por Ketter e Stoffel (2008, p.142),

\begin{abstract}
Until education faculty can devise more effective ways to make the tacit theorypractice connections more obvious and more powerful to prospective and practicing teachers who choose this vocation to work for social justice, the communication barriers between teacher educators and teachers will continue to produce misgivings about the uses of educational theory and a lack of respect for the work teachers and teacher educators do.
\end{abstract}

Assume-se, assim, a importância de existir uma maior e mais próxima relação e comunicação entre os professores no terreno e as instituições de formação de professores, afirmando e respeitando os saberes relativos à docência e todos os intervenientes no processo educativo. Neste sentido, defende-se uma colaboração entre todos os agentes educativos, possibilitando uma maior conexão entre teoria e prática.

De acordo com Malm (2009), existem quatro elementos básicos que possibilitam uma co-construção de conhecimentos profissionais por parte dos professores, assentes na partilha e colaboração entre os diferentes professores:

i) prática pedagógica partilhada, em que os professores trocam e partilham ideias relacionadas com a sua ação pedagógica, o que pode possibilitar uma efetiva mudança; 
ii) redes de aprendizagens colaborativas, em que se partilham os resultados da sua prática, para que se influenciem mutuamente;

iii) reflexão durante a prática educativa, que possibilita, à semelhança do que foi explorado, uma integração da teoria e prática e na reconstrução do conhecimento profissional;

iv) desenvolvimento e partilha dos aspectos filosóficos, éticos e morais relacionados com a prática docente.

Fica, portanto, patente que os professores, para terem possibilidade de aprender com e na sua comunidade escolar devem encarar os restantes colegas como recursos que possibilitam, através do diálogo, da partilha e da reflexão, compreender e melhorar as suas próprias práticas enquanto docentes (SIGUR_ARDOTTIR, 2005; ALARCÃO; CANHA, Supervisão e Colaboração: Uma relação para o desenvolvimento, 2013). Esta perspectiva é homóloga ao que Alarcão (2001b; 2003) apresenta como Escola Reflexiva, em que os professores, de forma colaborativa, reconhecem a necessidade de refletir para avaliar e refletir para formar, assumindo como indispensável a formação dos professores em colaboração com os restantes docentes da escola.

Este posicionamento relaciona-se com seguinte citação, que revela alguns elementos basilares no âmbito da formação de professores:

It has been acknowledged that teacher education takes place over time, that professional development needs to be about "culturebuilding”, not skills training (Lieberman \& Miller, 1994), and that teachers like all learners need multiple opportunities to link previous knowledge with new understandings.It has also been argued that genuine teacher learning that is linked to student learning and curricular reform must be deeply embedded in the daily life of schools and teaching (DarlingHammond, 1998; Elmore \& Burney, 1997) and must feature opportunities for teachers to inquire systematically about how teaching practice constructs learning opportunities for students (LITTLE, 1993; COCHRAN-SMITH, 2000, p. 17).

Tomando com base as linhas do autor, reconhece a importância de, durante o período de formação profissional, os professores em formação terem oportunidade de integrar os seus conhecimentos no âmbito da docência. A par disso, verifica-se a necessidade de integrar na formação o quotidiano das escolas e a discussão sistemática sobre as práticas dos professores em contexto, para que estes tenham possibilidade de, contínua e progressivamente, ter múltiplas experiências de aprendizagem no âmbito da docência.

Como já se abordou, a prática educativa supervisionada é, por excelência, o momento em que as instituições de formação de professores incluem esta vertente nos seus cursos. Contudo, tal como é alertado por Oliveira-Formosinho (2003), os processos de supervisão são suscetíveis a problemas, que podem ser identificados pelos professores em formação, supervisores cooperantes (professores do ensino não superior que acolhem e acompanham os professores em formação nas suas salas de aula, durante o processo de supervisão) e supervisores institucionais (professores do ensino não superior acompanham os professores em formação durante o processo de supervisão), e que requerem respostas institucionais por 
parte das organizações responsáveis pela formação de professores.

Tendo por base o que tem sido explorado ao longo do presente trabalho, assume-se que poderão existir algumas situações em concreto que poderão, eventualmente, dificultar o processo de supervisão inicial. Tomando como sustentação os pressupostos que indicam os elementos necessários para que a supervisão se afirme como um processo formativo relevante (o que foi explorado nos parágrafos anteriores), extrapolam-se, por contradição, os seguintes fatores que poderão marcar, negativamente, o processo de supervisão e, implicitamente, o processo formativo:

- Pouco tempo dedicado ao processo de supervisão, centrando a formação de professores nos componentes iminentemente teóricos, sobrevalorizando a teoria em detrimento da prática;

- Pouco tempo dedicado à consolidação e integração de aspectos teóricos no âmbito da docência, sobrevalorizando a prática em detrimento da teoria;

- Difícil (ou inexistente) relacionamento entre as instituições de ensino superior (instituições de formação de professores) e as escolas e professores que acolhem os professores em formação;

- Supervisores cooperantes que não desenvolvem mecanismos de acompanhamento, e mentoring, invisibilizando o processo colaborativo entre o professor em formação e o(s) professor(es) com mais experiência ${ }^{56}$;

- Dificuldade em se garantir que as escolas de acolhimento e os professores cooperantes tenham, efetivamente, competências pedagógicas que possibilitem aos professores em formação desenvolverem os seus saberes profissionais naquele contexto ${ }^{5}$;

- Escolas que acolhem os estudantes em formação, mas perpetuam paradigmas pedagógicos que não se coadunam com os da instituição de ensino superior, nomeadamente, a perspectiva de que a prática e a teoria não têm qualquer integração possível;

- Contextos educativos que desenvolveram modelos de supervisão distintos originando uma desconexão entre o modelo de supervisão da instituição de ensino superior, da escola e dos supervisores cooperantes;

\footnotetext{
${ }^{5}$ Estes dois fatores foram identificados por Altan e Sağlamel (2015). Mas reconhece-se a sua relevância neste contexto, uma vez que se relacionam com os pressupostos apresentados no âmbito da supervisão.

${ }^{6}$ Indica-se que este problema pode ser causado pela falta de formação específica por parte dos supervisores cooperantes, como é mencionado por Oliveira-Formosinho (2003) e Mesquita (2015).
} 
- Professores em formação que, sendo recebidos nas escolas, não são integrados na comunidade, uma vez que não existem mecanismos de colaboração que possibilitem integrar os professores de formação, sendo estes encarados como outsiders;

- Escolas/professores cooperantes que acolhem os professores em formação interpretam a presença dos supervisores institucionais como elementos externos, que além de acompanharem os professores em formação, servem como “inspetores” da instituição de ensino superior.

Como já foi aludido, o processo de supervisão é imprescindível para uma formação de professores em que esse processo se assume como especialmente relevante uma vez que possibilita a integração dos professores em formação com os contextos educativos concretos (OLIVEIRA-FORMOSINHO, 2003; MALM, 2009; IBARA, 2013; CHERUVUA, 2014; MCKENZIE, 2015). A esta perspectiva, alia-se a consideração que o professor, através de processos colaborativos dentro da própria profissão docente, com o desenvolvimento de comunidades de prática, tem possibilidade de desenvolver os seus próprios saberes profissionais enquanto docentes (SIGUR_ARDOTTIR, 2005; MESQUITA; FORMOSINHO; MACHADO, Supervisão da Prática Pedagógica e colegialidade docente. A perspetiva dos candidatos e professores, 2012; SULTANA, 2005), sendo por isso essencial a relação entre as escolas e as instituições de formação de professores (COCHRAN-SMITH, 2000).

Todavia, tal como é alertado por Alarcão e Canha (2013, p. 58), "Para haver comunidade, é necessário haver um percurso de experiência alargado no tempo, uma história construída em conjunto que consolidada e pertença e a confiança mútua e que permite antever um futuro de continuidade”.

De forma a que as instituições de superior tenham possibilidade de integrar os professores em formação nas escolas não-superiores, de maneira que estes sejam parte integral da comunidade, que se estabeleça o continuum de experiências e história que os autores defenderam. Ainda se indica que esse continuum colaborativo torna-se essencial na resposta aos problemas já apresentados.

Desta forma, e tendo em consideração tudo o que foi apresentado, propõe-se a criação de comunidades de educativas e pedagógicas com a inclusão das instituições de ensino superior e das escolas de ensino não superior. Usando-se o sistema português, esquematizouse da seguinte forma, ilustrando duas Comunidades Educativas e Pedagógicas (Esquema 2). 


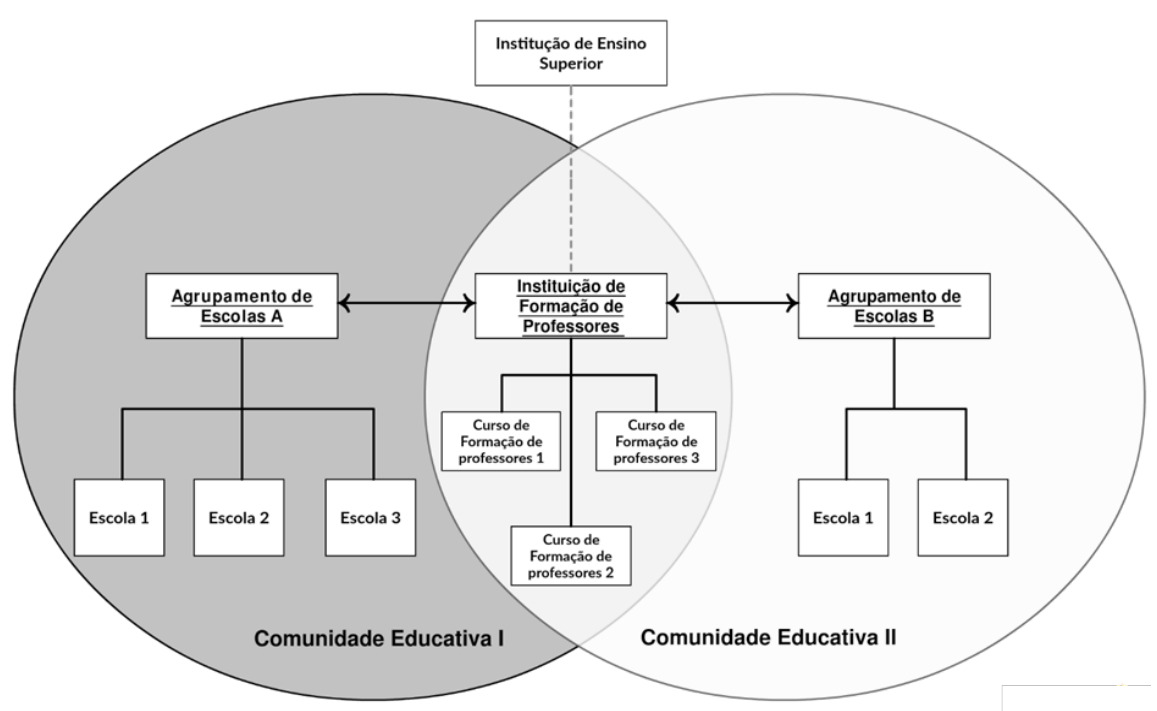

Esauema 2 -Comunidades Educativas e Pedagógicas. Fonte: construcão

Estruturou-se o esquema apresentado duas Comunidades Educativas Pedagógicas, de forma a ilustrar a possibilidade da existência de várias relações possíveis, mediante a necessidade das Instituições de Formação de Professores (ou quaisquer outras instituições específicas no âmbito da formação de professores), e o contexto em que está inserido. De forma similar, optou-se por considerar que os Agrupamentos de Escola tinham números de escolas diferentes (um contempla três escolas de ensino não superior e outro integra duas escolas do ensino não superior), e as Instituições de Formação de Professores apresentavam três ofertas formativas no contexto da formação de professores. Reconhece-se, porém, que cada contexto tem as suas próprias características e que no esquema estereotipou-se dessa forma, enquanto modelo explicativo.

Estas Comunidades Educativas e Pedagógicas poderiam, em última análise, partilhar infraestruturas, recursos e materiais, corpo docente e restantes funcionários, ainda que cada entidade (Instituições de Formações de Ensino e Agrupamento de Escolas) mantivesse a sua autonomia e identidade. Contudo, tendo em conta a existência (em funcionamento) de sistemas que não possibilitam esta estrutura, a proposta que se defende centra-se no plano relacional das duas organizações, nos seguintes aspectos:

- Desenvolvimento de projetos comuns entre o Agrupamento de Escolas e a Instituição de Formação de Professores com a participação de estudantes e professores das duas organizações. Retomando a citação de Alarcão e Canha (2013), reconhece-se que a construção e desenvolvimento de projetos comuns é essencial para a afirmação de reais comunidades;

- Partilha de recursos, materiais e opções pedagógicas, uma vez que se assume que estes elementos são essenciais para a prática pedagógica, reconhece-se a sua importância no processo formativo dos professores. Também se reconhece que os professores do ensino não superior poderão contribuir, significativamente, para a formação dos futuros professores, 
através da partilha - durante a formação superior dos estudantes/ futuros docentes - dos materiais e recursos que se usam em contexto escolar, assim como das suas opções metodológicas;

- Integração das duas instituições em processos de avaliação interna de cada uma das organizações. Assume-se que o processo de avaliação interna das organizações educativas é essencial para a tomada de decisões administrativas (MACHADO, 2010), que visam, tendo em conta a incerteza que marca a época contemporânea, desenvolver mecanismos que melhor permitem responder aos desafios atuais (COSME; TRINDADE, 2010). Em concomitância com estes pressupostos, reconhece-se que este processo deve envolver um espectro alargado de participantes, de forma a incluir todos os membros que constituem a comunidade escolar (FORMOSINHO; MACHADO, 2010). De acordo com o apresentado, reconhece-se que a integração de elementos da Instituição de Formação de Professores na avaliação interna dos Agrupamentos de Escola (e vice versa) - não como elementos externos, mas como representantes da comunidade educativa -, apresenta-se como um aspecto enriquecedor que integra os elementos das duas organizações e possibilita a continuidade na afirmação de uma comunidade comum;

- Integração dos estudantes do ensino superior nas escolas do agrupamento desde do início da formação profissional. Como é referido por Altan e Sağmel (2015), os futuros professores devem vivenciar um conjunto vasto de experiências, antes de lecionar em contexto de sala de aula. Dessa forma, com este tipo de comunidade, os professores em formação poderiam observar e refletir com os professores do Agrupamento, e até promover atividades pedagógicas específicas (acompanhamento ao estudo, atividades relativas a datas festivas, desenvolvimento de tarefas pedagógicas próprias - planeadas na Instituição de Formação de Professores -, etc.). Deste modo, os futuros professores iriam se integrando na comunidade escolar, nas suas rotinas e especificidades muito antes do processo formal de supervisão, o que seria um processo contínuo e sistemático de aprendizagem.

- Articulação das instituições em momentos de reflexão sobre as práticas pedagógicas. Indo ao encontro da Escola Reflexiva (ALARCÃO, Escola Reflexiva, 2001b; 2003) ou a Comunidade de Prática (SIGUR_ARDOTTIR, 2005; MESQUITA, FORMOSINHO; MACHADO, Supervisão da Prática Pedagógica e colegialidade docente. A perspetiva dos candidatos e professores, 2012; SULTANA, 2005), torna-se inegável o contributo da reflexão colaborativa no processo de melhoria e transformação do processo educativo do coletivo. Dessa forma, e de acordo com essa perspectiva, a inclusão de elementos da Instituição de Formação de Professores (professores e estudantes) nessa reflexão é, indubitavelmente, um contributo essencial. Contudo, reconhece-se, que esse contributo só é positivo se todos os intervenientes conhecerem o contexto e as práticas sobre os quais está incidindo a reflexão, pelo que é essencial que haja uma contínua e sistemática presença de todos os elementos das escolas não superiores.

- Articulação das instituições em processos investigativos/académicos. Como é alertado por 
Ketter e Stoffel (2008), é possível a existência de alguma tensão entre a comunidade académica e a comunidade docente. Em parte, porque há quem considere que os projetos de investigação desenvolvidos não têm qualquer, ou nenhum, impacto nas decisões políticas ou nas salas de aula. Dessa forma, ao possibilitar-se que os professores do ensino não superior e os professores ${ }^{7}$ do ensino superior colaborassem e desenvolvessem, de forma sistemática e contínua, diferentes projetos investigativos e ações formativas aos professores em formação, considera-se que seria possível contrariar esta ideia, fortalecendo as relações entre as instituições e, também, entre a teoria e prática, como já foi explorado em parágrafos anteriores.

Face ao que foi apresentado, reconhece-se que a construção de comunidades com a presença de escola de ensino superior e de ensino não superior pode ser extremamente enriquecedor para a formação de professores. Esta dinâmica possibilita, por um lado, a contínua e progressiva integração dos estudantes no contexto escolar, fazendo com que, durante o período da prática educativa supervisionada, os professores em formação já conheçam o contexto e tenham possibilidade de interagir com os seus intervenientes de uma forma mais profunda e natural. Por outro lado, ao aproximar as escolas de ensino superior e as escolas do ensino não superior, é possível conferir maior coesão ao processo formativo, uma vez que a sua interação mais próxima vai dar um mais profundo e mais complexo contributo na formação inicial de professores. Por último, esta coesão é fundamental enquanto resposta aos desafios identificados no âmbito da supervisão inicial. Ao existir uma relação próxima entre as duas instituições, o processo de supervisão vai, continuamente, ser mais integrado na comunidade escolar, uma vez que todos os intervenientes partilham e refletem sobre os diferentes paradigmas sobre a supervisão e os aspectos educativos no geral.

Este tipo de prática implica a contínua e sistemática relação entre Instituição de Formação de Professores e Agrupamento de Escolas, sendo que este processo vai possibilitar a construção de uma comunidade que reflete de forma colaborativa e se afirma como fulcral na formação inicial dos professores. A par disso, este tipo de relação promove a afirmação e consolidação de práticas de reflexão e investigação que são basilares para o contínuo processo de transformação da prática pedagógica e para a consolidação dos conhecimentos inerentes à docência que influenciam a formação dos professores. Desta forma, esta comunidade é consolidada na prática, na teoria e na relação entre a prática e a teoria, possibilitando uma formação integral dos futuros professores, mas também, a afirmação da comunidade como um centro pedagógico onde se reflete sobre práticas reais, contextualizando os problemas inerentes à docência.

\footnotetext{
${ }^{7}$ Os estudantes do ensino superior também poderão colaborar com este processo investigativo.
} 


\section{Notas Finais}

O trabalho desenvolvido apresenta algumas propostas que possibilitam a reflexão e discussão sobre aspectos relacionados com a docência e com a formação inicial de professores. De acordo com o que foi estudado nos parágrafos anteriores, centra-se a formação dos professores em contextos universitários e académicos, uma vez que, à semelhança de Mesquita (2015), se considera que a formação de professores tem como principais responsáveis as instituições de ensino superior. Contudo, o que foi apresentado não ignora as dinâmicas colaborativas de aprendizagem, nem a importância da formação em contexto.

Por um lado, reconhece-se que no âmbito da supervisão se pretende colmatar esta situação, pelo outro lado, também se verifica que a supervisão, por si só, não é suficiente. O que foi explorado, possibilita uma maior integração dos professores em formação às práticas, costumes e quotidiano da escola, mas também auxilia no processo de reflexão e transformação das próprias escolas que os acolhem, num processo contínuo e recíproco. O trabalho apresentado reconhece a imensa relevância da colaboração entre as instituições de ensino superior e as escolas de ensino não superior, mas, a par disso, assume como indispensável a continuidade e reciprocidade deste processo. Através desta comunidade assume-se, à semelhança de Caires, Almeida e Vieira (2012), a importância de se assumir a responsabilidade e cooperação entre os professores do terrenos com os supervisores do ensino superior, possibilitando uma real articulação entre eles na construção de estratégias e práticas de supervisão.

Desta forma, pretende-se aprofundar a coesão e coerência do processo formativo (no âmbito da formação inicial dos professores) no seu todo, nos componentes práticos e nos componentes teóricos (ou mais académicos), para que o saber profissional dos estudantes em formação superior seja globalizado e globalizante, em que, efetivamente, a teoria e a prática se conjugam num saber praxiológico construído individualmente, mas através de um real processo colaborativo de todos os intervenientes, que não se limita ao processo da Prática Educativa Supervisionada.

\section{Referências}

AFONSO, Almerindo Janela. Trabalho docente em tempo de crise(s). In: MACHADO, J.; ALVES J. M. (Org.). Escola para todos: igualdade, diversidade e autonomia. Porto: Universidade Católica Editora, 2014. p. 41-56.

AIMARETTI, Edit Susana Alberto. Formación de docentes para los niveles inicial y primario. Revista Ibero-americana de Educação, v. 67, n. 2, p. 131-142, 2015.

ALARCÃO, Isabel. Reflexão crítica sobre o pensamento de D. Schön e os programas de formação de professores. Revista Faculdade de Educação, São Paulo, v. 22, n. 2, 11-42, 1996. 
ALARCÃO, Isabel. Professor-investigador: que sentido? que formação? In: CAMPOS, B.P. (Org.). Formação profissional de professores no ensino superior. Porto: Portro Editora, 2001a. p.21-31. (Cadernos de Formaçao de Professores; 1)

ALARCÃO, Isabel. Escola reflexiva. In: ALARCÃO, I. (Org.). Escola reflexiva e nova racionalidade. Porto Alegre: Artmed Editora, 2001b. Cap. 1, p. 15-30.

ALARCÃO, Isabel. Professores reflexivos em escola reflexiva. São Paulo: Cortez, 2003.

ALARCÃO, Isabel.; CANHA, B. Supervisão e colaboração: Uma relação para o desenvolvimento. Porto: Porto Editora, 2013.

ALTAN, Mustafa Zülküf.; SAğLAMEL, Hasan. Student teaching from the perspectives of cooperating teachers and pupils. Cogent Education, v. 2, p. 1-16, 2015.

CAIRES, S.; ALMEIDA, L.; VIEIRA, D. Becoming a teacher: student teachers' experiences and perceptions about teaching practice. European Journal of Teacher Education, v. 35, n. 2, p. 163-178, 2012.

CHERUVUA, Ranita. Focus on teacher as researcher: teacher educators as teacher researchers: Practicing What We Teach. Childhood Education, v. 90, n. 3, p. 225-228, 15 Apr 2014.

COCHRAN-SMITH, Marilyn. The future of teacher education: Framing the questions that matter. Teaching Education, v. 11, n. 1, p. 13-24, 2000.

COSME, Ariana.; TRINDADE, Rui. Avaliar as Escolas: Para quê e Porquê? Revista do Centro de Formação Francisco de Holanda, p. 33-40, 2010.

CUNHA, António. Camilo. Ser professor: bases de uma sistematização teórica. Braga: Casa do Professor, 2008.

ESTRELA, Maria Teresa; FREIRE, Isabel. Nota de apresentação: formação de professores. Sísifo / Revista de Ciências da Educação, v. 8, p. 3-5, 2009.

FLORES, Maria Assunção. Algumas reflexões em torno da formação inicial de professores. Educação, Porto Alegre, v. 33, n. 3, p. 182-188, 2010.

FORMOSINHO, João. Do modo de aprender ao modo de colaborar. Para uma pedagogia da colaboração docente. In: FORMOSINHO, J.; MACHADO, J.; MESQUITA, E. Formação, trabalho e aprendizagem. Tradição e inovação nas práticas docentes. Lisboa: Edições Sílabo, 2015. p. 9-18.

FORMOSINHO, João.; MACHADO, Joaquim. Escola, Auto-Avaliação e Desenvolvimento Organizacional. Revista do Centro de Formação Francisco de Holanda, p. 41-50, 2010.

HAGGARTY, Linda. What does research tell us about how to prepare teachers? ESCalete PGCE. University of Nottingham: [s.n.]. 2002.

\begin{tabular}{l|l|l|l|l|l|l} 
(C) Rev. Inter. Educ. Sup. & Campinas, SP & v.2 & n.3 & p.405-429 & set./dez. 2016 & ISSN 2446-9424
\end{tabular}


IBARA, E. C. Exploring clinical supervision as instrument for effective teacher supervision. Africa Education Review, v. 10, n. 2, p. 238-252, 2013.

KETTER, Jean; STOFFEL, Brian. Getting Real: Exploring the perceived disconnect between education theory and practice in teacher education. Studying Teacher Education, v. 4, n. 2, p. 129-142, 2008.

LARRIVEE, Barbara. Transforming Teaching Practice: becoming the critically reflective teacher. Reflective Practice, v. 1, n. 3, p. 293-307, 2000.

MACHADO, Eusébio Andrade. Auto-avaliação de escola: Que lógica(s) de Regulação? Revista do Centro de Formação Francisco de Holanda, p. 23-32, 2010.

MALM, Birgitte. Towards a new professionalism: enhancing personal and professional development in teacher education. Journal of Education for Teaching, v. 35, n. 1, p. 77-1, 2009.

MARCELO, Carlosa. Desenvolvimento Profissional Docente: passado e futuro. Sísifo / Revista de Ciências da Educação, v. 8, n. 1, p. 7-22, 2009.

MCKENZIE, Liz. Trainee teachers' experience of reflection. Journal of Further and Higher Education, p. 1-20, 2015.

MESQUITA, Elza. Formação inicial, profissão docente e competências para a docências. A visão dos futuros professores. In: FORMOSINHO, J.; MACHADO, J.; MESQUITA, E.

Formação, trabalho e aprendizagem. Tradição e inovação nas práticas docentes. Lisboa: Edições Sílabo, 2015.

MESQUITA, Elza; FORMOSINHO, João.; MACHADO, Joaquim. Supervisão da Prática Pedagógica e colegialidade docente. A perspectiva dos candidatos e professores. Revista Portuguesa de Investigação Educacional, v. 12, p. 59-77, 2012.

MESQUITA, Elza.; FORMOSINHO, João.; MACHADO, Joaquim. Formação e trabalho: tradição e inovação nas práticas docentes. In: LOPES, A., et al. Trabalho docente e formação | Políticas, práticas e investigação: pontes para a mudança. [S.l.]: CIIE - Centro de Investigação e Intervenção Educativas, 2014. p. 347-358.

NÓVOA, António. Formação de Professores e Profissão Docente. In: NÓVOA (ORG.), A. Os professores e a sua formação. Lisboa: Dom Quixote, 1992. p. 313-330.

NÓVOA, António. Os professores e o "novo" espaço público da educação. In: NÓVOA, António. Formação de professores e trabalho pedagógico. Lisboa: Educa, 2002. p. 3-30.

NÓVOA, António. O regresso dos professores. Comunicações. Conferência Desenvolvimento profissional de professores para a qualidade e para a equidade da Aprendizagem ao longo da vida. Lisboa: Presidência portuguesa do Conselho da União Europeia. 2007a. 
NÓVOA, António. Nada substitui o bom professor. Desafios do trabalho do professor no mundo contemporâneo. Vila Clementino: Sindicato de Professores de São Paulo. 2007b. p. 520.

NÓVOA, António. Professores: imagens do futuro presente. Lisboa: Instituto de Educação da Universidade de Lisboa, 2009.

NUNES, Cely do Socorro Costa.; NUNES, Herica Socorro da Costa. A formação inicial de professores em Portugal: hoje em dia, todo professor deve ser. Educação em Perspectiva, Viçosa, v. 4, n. 1, p. 224-237, 2013.

OLIVEIRA, Isolina.; SERRAZINA, Lurdes. A reflexão e o professor como investigador. Reflectir e investigar sobre a prática profissional, Lisboa: APM, p. 29-42, 2002.

OLIVEIRA-FORMOSINHO, Júlia. A supervisão pedagógica da formação inicial de professores no âmbito de uma comunidade de prática. In: IGLESIAS, M. L., et al. VII

Symposium Internacional sobre el Practicum - Practicum y Prácticas en empresas en lá formación universitaria. Pontevedra: Servixo de Edición Dixital da Universidade de Santiago de Compostela, 2003. p. 37-63. Disponivel em:

$<$ http://redaberta.usc.es/poio/documentos/actas/actas_poio_2003.pdf>.

PÉREZ GÓMEZ, Ángel. Aprender a educar. Nuevos desafíos para la formación de docentes. Revista Interuniversitaria de Formación del Profesorado, v. 68, n. 24,2, p. 37-60, 2010.

PERRENOUD, Philippe. Formar professores em contextos sociais em mudança | Prática reflexiva e participação crítica. Revista Brasileira de Educação, v. 12, p. 5-21, 1999.

Disponivel em:

<http://www.unige.ch/fapse/SSE/teachers/perrenoud/php_main/php_1999/1999_34.html>.

PERRENOUD, Philippe. Dez novas competências para uma nova profissão. Pátio. Revista pedagogica, v. 17, p. 8-12, 2001.

RIBEIRO, Deolinda. Supervisão e o desenvolvimento da profissionalidade docente. In: ALRCÃO, I. Escola Reflexiva e Supervisão. Porto: Porto Editora, 2000. p. 87-96.

RIBEIRO, Deolinda. Um olhar na mudança de orientações para a formação de professores em Portugual. Desafios Curriculares e Pedagógicos na Formação de Professores. Braga: Centro de Investigação em Estudos da Criança (CIEC) | Universidade do Minho. 2015. p. 358-365.

ROLDÃO, Maria do Céu. Gestão curricular - fundamentos e práticas. Lisboa: Ministério da Educação - Departamento de Educação Básica, 1999.

ROLDÃO, Maria do Céu. Professores para quê? Para uma reconceptulização da formação de profissionais de ensino. Discursos: Perspectivas em Educação, p. 95-120, 2004.

ROLDÃO, Maria do Céu. Prossionalidade docente em análise: especifidades dos ensinos superior e não superior. Nuances: Estudos sobre a Educação, v. 12, n. 13, p. 105-127, 2005. 
ROLDÃO, Maria do Céu. Função docente: natureza e construção do conhecimento profissional. Saber (e) Educar, v. 13, p. 171-184, 2008.

ROLDÃO, Maria do Céu. Para que serve a supervisão? In: MACHADO, J.; ALVES, J.M. (Coord.). Coordenação, supervisão e liderança. Porto: Universidade Católica Editora, 2014. p. 36-47.

ROLDÃO, Maria do Céu. Professores: dilema de uma transformação. In: MACHADO, J.; ALVES, J. M. (Org.). Escola para todos: igualdade, diversidade e autonomia. Porto: Universidade Católica Editora, 2014. p. 57-68.

SHULMAN, Lee S. Those who understand: knowledge growth in teaching. Educational Researcher, v. 15, n. 2, p. 4-14, 1986.

SHULMAN, Lee S. Knowledge and teaching: foundations of the New Reform. Harvard Educational Revew, v. 57, n. 1, p. 1-21, 1987.

SIGUR_ARDOTTIR, Anna Kristín. Studying and enhancing professional learning community for school efectiveness in iceland. REICE - Revista Electrónica Iberoamericana sobre Calidad, Eficacia y Cambio en Educación, v. 3, n. 1, p. 178-193, 2005. Disponivel em: <http://www.ice.deusto.es/rinace/reice/vol3n1_e/Sigurardottir.pdf>.

SULTANA, Ronald G. The initial education of high school teachers: a critical review of major issues and trends. Studying Teacher Education, v. 1, n. 2, p. 225-243, 2005.

VIEIRA, Flávia. Para uma visão transformada da supervisão pedagógica. Educação \& Sociedade, Campinas, v. 30, n. 106, p. 197-217, 2009.

YOUNG, Jon; BOYD, Karen. More Than Servants of the State? The governance of initial teacher preparation in Canada in an era of school reform. The Alberta Journal of Educational Research, v. 56, n. 1, p. 1-18, 2010.

ZEICHNER, Kennethe. M. A Formação reflexiva de professores: ideias e práticas. Tradução de A. J. Carmona Teixeira; Maria de Carvalho e Maria Nóvoa. Lisboa: EDUCA, 1993. 